\title{
Sistema Nervioso Central y Regulación de la Respuesta Inmune
}

\author{
Ulises Vergara C. ${ }^{1,2}$ \\ ${ }^{1}$ Laboratorio de Inmunología, Departamento de Medicina Preventiva, Facultad de Ciencias \\ Veterinarias, y Pecuarias, Universidad de Chile. Av. Santa Rosa 11735, La Pintana, Santiago, \\ Chile. Correo 2, Casilla 15, La Granja. \\ ${ }^{2}$ Escuela de Postgrado, Facultad de Medicina, Universidad de Chile. Av. Independencia 1027, \\ Santiago, Chile.
}

\begin{abstract}
Resumen
El sistema nervioso central (SNC) ha sido tradicionalmente considerado como un tejido inmunologicamente privilegiado puesto que está protegido del medio periférico continuamente cambiante, por una barrera denominada "barrera hematoencefálica"; el SNC carece de las clásicas células presentadoras de antígeno, como las células dendríticas; el SNC carece además de la expresión constitutiva de moléculas de presentación antigénica MHC de clase I y de clase II y los vasos linfáticos no se encuentran presentes en el cerebro. Sin embargo, en los últimos años se ha hecho necesario reevaluar este dogma puesto que los datos actuales sugieren que el SNC participa activamente en la regulación de la respuesta immune, mediante la liberación de neurotransmisores que pueden ejercer una importante influencia en la función de las células del sistema inmune, las cuales expresan receptores de membrana que transducen señales específicas, luego del reconocimiento y unión de tales neurotransmisores. Por otro lado, las células microgliales, que representan las células más importantes del sistema inmune innato en el cerebro, expresan receptores similares a los receptores Toll (TLRs: Toll-like receptors), responden a ligandos TLR, producen mediadores proinflamatorios y responden rápidamente frente a patógenos o frente al daño tisular, acumulándose en las regiones cerebrales donde se produce neurodegeneración o daño. Ha resultado también interesante el hecho que las células microgliales puedan activarse frente a infecciones sistémicas, en ausencia de un compromiso de la barrera hematoencefálica. Adicionalmente la inmunovigilancia rutinaria del SNC, requiere el ingreso de linfocitos T activados, células dendríticas y macrófagos que pueden penetrar el endotelio vascular del cerebro, aún en condiciones aparentemente fisológicas. Sin embargo, en condiciones normales los linfocitos T no pueden ingresar en el parénquima cerebral y se acumulan en los espacios perivasculares (Virchow-Robin) y subaracnoideo. Finalmente, los leucocitos no sólo expresan receptores para neurotransmisores como glutamato, dopamina, aceticolina y serotonina, sino que también pueden liberarlos de manera que pueden actuar como moduladores autocrinos y paracrinos.
\end{abstract}

Palabras clave: Privilegio Inmune Cerebral, Inmunoregulación Por Neurotransmisores, Células Microgliales, Linfocitos T Activados, Inmunovigilancia Cerebral, Neurodegeneración, Glutamato, Dopamina, Acetilcolina, Serotonina.

\section{Introducción}

El Sistema Nervioso Central (SNC) ha sido tradicionalmente considerado como inmunológicamente privilegiado puesto que está protegido por una barrera hematoencefálica, carece de vasos linfáticos, está desprovisto de células dendríticas y las células del parénquima no expresan moléculas presentadoras de antígeno MHC de clase I y de clase II. 
Sin embargo, en los últimos años se ha hecho necesario reevaluar este dogma a la luz de hallazgos que sugieren que el $\mathrm{SNC}$ es no sólo claramente inmunocompetente, sino que tiene también la capacidad de interactuar con el sistema inmune periférico, a través de la síntesis y liberación de neurotransmisores que pueden regular la diferenciación y funcionamiento, tanto de células de la inmunidad innata como de la inmunidad adquirida. De esta manera el SNC puede modular la respuesta inmune y limitar el daño tisular inducido por inflamación (Engelhardt and Ransohoff, 2005, Levite, 2008; Tian y col., 2009)

La producción de citoquinas por el sistema inmune contribuye de manera importante, tanto en la mantención de la salud de los individuos, como en el desarrollo de enfermedad. Así, la activación del sistema inmune innato, y la consiguiente síntesis y secreción de citoquinas como TNF, IL-1, IL-6 y otros mediadores solubles, que tienen la capacidad de inducir daño tisular y un conjunto síntomas y signos conocidos como el "síndrome de enfermedad" (fatiga, fiebre, anorexia, decaimiento), conduce inevitablemente a la puesta en marcha de mecanismos de regulación que permiten mantener el estado de salud, limitando la producción y toxicidad de estos mediadores.

Las neuronas del SNC participan activamente en el control de la respuesta inmune al modular la función de las células gliales y de linfocitos $\mathrm{T}$, tanto por mecanismos que implican contacto directo a través de glicoproteínas de membrana como CD22, CD47, CD200, neural cell adhesion molecule (NCAM o CD56), intercellular cell adhesión molecule-1 (ICAM-1), semaforinas y caderinas, como por mecanismos independientes del contacto célula-célula y que implican la expresión del ligando de Fas o CD95L, que promueve la apoptosis de células microgliales y de linfocitos T (Rivest, 2009; Tian y col, 2009)

\subsection{Control reflejo de la respuesta inmune.}

En los últimos años se ha hecho evidente que el sistema inmune no es un sistema completamente autónomo, puesto que los órganos linfoides están inervados por neuronas colinérgicas, catecolaminérgicas, peptidérgicas y otras neuronas (Tracey, 2009). Así, el sistema nervioso y el sistema inmune pueden interactuar, no sólo a través del eje hipotálamo-hipófisis-adrenal, cuya activación conduce a la síntesis de corticoesteroides que inhiben la respuesta inmune, sino que también pueden hacerlo mediante circuitos neuronales del nivel central (ReyesGarcía y García-Tamayo, 2009) y a través del sistema nervioso autónomo, tanto simpático como parasimpático, que mediante circuitos sensoriales $\mathrm{y}$ efectores trasmiten impulsos que inducen, de manera refleja, la puesta en marcha de una respuesta antiinflamatoria. (Elenkov y col., 2000; Bellinger y col., 2008).

En condiciones fisiológicas las fibras sensoriales y aferentes del sistema nervioso autónomo, viajan con el nervio vago, desde los tejidos periféricos hasta el SNC para proporcionar información acerca del normal funcionamiento tisular o del eventual desarrollo de un proceso inflamatorio inducido por citoquinas, sintetizadas por células de la inmunidad innata, en respuesta a la presencia de agentes infecciosos o de moléculas propias liberadas como consecuencia de un daño tisular en esos órganos periféricos. El estimulo sensorial aferente gatilla, en el SNC, una respuesta que incluye los síntomas y signos del síndrome de enfermedad y un circuito o vía simpática eferente, llamado reflejo colinérgico antiinflamatorio que, a través del nervio vago, puede inhibir la síntesis de citoquinas proinflamatorias y, por lo tanto, limitar o prevenir el eventual daño tisular producido por estos mediadores (Tracey, 2007).

Citoquinas proinflamatorias como TNF, IL-1 e IL-6, producidas durante la activación de células de la inmunidad innata en los tejidos periféricos, son capaces de modular la actividad de circuitos neuronales del SNC a través de receptores específicos expresados por neuronas del hipotálamo y otras regiones del cerebro. Se induce, de esta manera, una respuesta caracterizada por la transmisión de potenciales de acción que desencadenarán los síntomas y signos, locales y sistémicos, del "sindrome de enfermedad", el que será luego controlado por la vía vagal colinérgica y anti-inflamatoria. Esta respuesta del SNC, no sólo conduce a controlar la progresión del proceso inflamatorio en el tejido periférico, sino también a prevenir un eventual daño tisular inmunomediado, dado que las células del sistema inmune expresan receptores para numerosos neurotransmisores inhibitorios 
(Tracey, 2010). Así, la activación inmunológica de este circuito neuronal, confiere protección contra el daño tisular inhibiendo la liberación de citoquinas durante una infección, autoinmunidad, shock y otros síndromes inflamatorios (Figura 1).

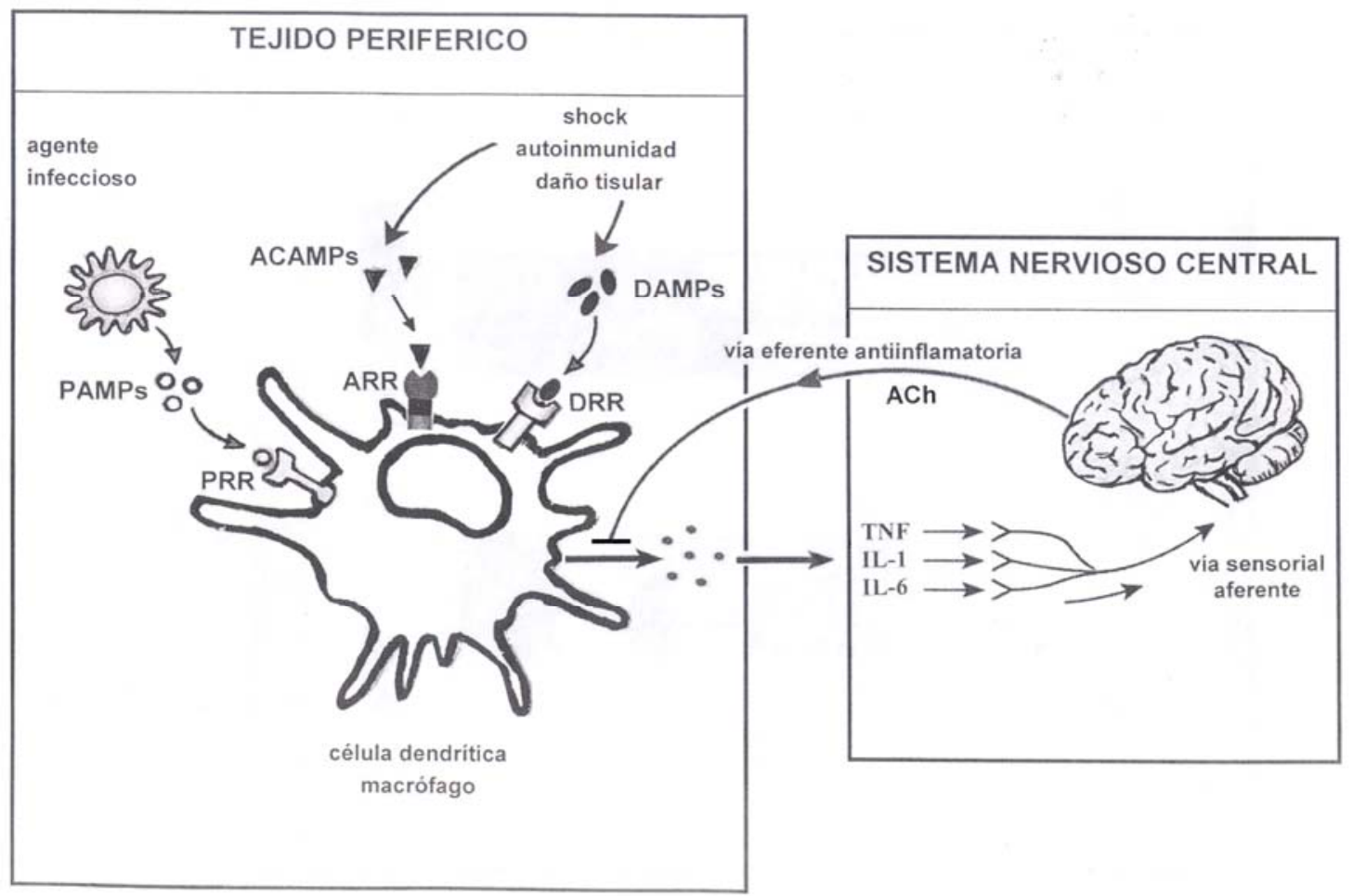

Figura 1. El sistema nervioso y el sistema inmune interactúan, no sólo mediante diversos circuitos neuronales a nivel central, sino también a través del sistema nervioso autónomo, tanto simpático como parasimpático, el cual mediante circuitos neuronales sensoriales y efectores transmite potenciales de acción que, de manera refleja, activan la puesta en marcha de una vía vagal antiinflamatoria mediada por acetilcolina (ACh).

La respuesta inflamatoria frente a agentes infecciosos (respuesta contra "lo extraño"), a la conformación o plegamiento anormal de proteínas y su consecuente agregado y acumulación intracelular en células propias normales, o al daño tisular (respuesta contra una "señal de peligro"), es siempre iniciada por células de la inmunidad innata y en particular, por células dendríticas y macrófagos. Estas células pueden activarse a través de receptores PRRs (PAMP Recognition Receptors), que reconocen patrones moleculares propios de agentes infecciosos (PAMPs: Pathogen Associated Molecular Paterns), de receptores DRRs (DAMP Recognition Receptors) que reconocen patrones moleculares propios del tejido dañado (DAMPs: Damage Associated Molecular Patterns) o bién a través de receptores ARRs (ACAMP Recognition Receptors) que reconocen patrones moleculares propios de células en apoptosis (ACAMP: Apoptotic Cell Associated Molecular Pattern). De esta manera se activa la síntesis y secreción de citoquinas, como TNF, IL-1 e IL-6, que no sólo inducirán el desarrollo de un proceso inflamatorio, sino que también estimularán la liberación de diversos neurotransmisores por distintos circuitos neuronales. Es así como los neurotransmisores liberados por el SNC o por el sistema nervioso autónomo, inhibirán la síntesis y secreción de estas citoquinas proinflamatorias, luego de su reconocimiento por receptores específicos existentes en la membrana plasmática de las células de la inmunidad innata, disminuyendo así el riesgo de un eventual daño tisular inducido por estos mediadores. 


\subsection{Neurotransmisores $y$ regulación de la respuesta inmune}

Los neurotransmisores son moléculas solubles secretadas por neuronas, se encuentran presentes en las terminaciones presinápticas y pueden regular la actividad de neuronas postsinápticas y de diversos órganos efectores, entre ellos los órganos linfoides primarios y secundarios, que se encuentran altamente inervados por fibras nerviosas que no sólo almacenan altos niveles de algunos neurotransmisores, sino que se encuentran también en contacto directo, tanto con células presentadoras de antígeno como con linfocitos $\mathrm{T}$ y linfocitos B (Levite, 2008). Además, muchos neurotransmisores pueden unirse no sólo a receptores específicos expresados en células del sistema nervioso central y del sistema nerviosos periférico, sino que pueden también unirse a receptores presentes en la membrana de distintas poblaciones celulares inmunocompetentes y cuya expresión es regulada por citoquinas, los neutransmisores mismos y otros factores (Levite, 2008; Reyes-García y García-Tamayo, 2009). En los linfocitos $\mathrm{T}$, un neurotransmisor determinado podrá activar o inhibir la diferenciación y/o función linfocitaria, dependiendo del estado de activación celular, del subtipo de receptor expresado por el linfocito, de los niveles del neurotransmisor, de la liberación simultánea de otros neurotransmisores, de la presencia de un particular patrón de citoquinas, quimioquinas y factores de crecimiento $\mathrm{y}$, finalmente, de la subpoblación TCD4 o TCD8 que está sufriendo los efectos del neurotransmisor (Levite, 2008).

En términos generales los neurotransmisores, que pueden activar o inhibir diversas funciones neuronales y linfocitarias, se separan en tres categorías químicas distintas:

- Aminoácidos como glutamato, glicina y ácido gama butírico

- Aminas biogénicas como dopamina, adrenalina, noradrenalina y serotonina.

- Neuropéptidos o neurotransmisores peptidérgicos, como somatostatina, substancia $\mathrm{P}, \quad 44$ neuropéptido $\mathrm{Y}$, opioides, polipéptido intestinal vasoactivo, calcitonina, neurotensina, bombasina, galanina, motilina y otros ( Levite, 2008; ReyesGarcía y García-Tamayo, 2009).
En relación al sistema inmune, los mecanismos tradicionales de regulación de la respuesta inmunológica, tanto en los órganos linfoides secundarios como en los tejidos periféricos, incluyen:

- La interacción entre distintas subpoblaciones celulares, que incluyen: linfocitos $\mathrm{T}$, linfocitos $\mathrm{B}$, células presentadoras de antígeno (como células dendríticas y macrófagos), células NK y diversas células accesorias (como neutrófilos, eosinófilos, basófilos, mastocitos, células endoteliales, etc);

- La síntesis y secreción de diversos mediadores solubles (citoquinas, quimioquinas,

- Leucotrienos, protaglandinas);

- La regulación idiotípica (red idiotipoantiidiotipo);

- La regulación hormonal a través del eje hipotálamo-hipófisis-adrenal;

- El feedback por anticuerpos y la activación de linfocitos $\mathrm{T}$ reguladores (Wing Y Sakaguchi, 2010, Sakaguchi y col., 2010; Vergara y col., 2002, Vergara, 2009).

Sin embargo, en los últimos años se ha hecho evidente que la magnitud y naturaleza de la respuesta inmune puede ser también regulada por neurotransmisores como dopamina (DA), glutamato (Glu), aceticolina (Ach), ácido gamabutírico (GABA), Noradrena- lina/Adrenalina (NA/A) y serotonina o 5-hidroxitriptamina (5HT), liberados por el SNC (Levite, 2006; Franco y col., 2007, Pacheco y col., 2009). Los hallazgos indican además, que las células del sistema inmune pueden expresar receptores para diversos neurotransmisores, entre los cuales se encuentran: glutamato (Pacheco y col., 2007), dopamina (Besser y col., 2005, Saha y col., 2001; Sarkar y col., 2006; Watanabe y col., 2006), serotonina (León-Ponte y col., 2007), acetilcolina (Kawashima y col., noradrenalina/adrenalina (Elenkov y col., 2000) y ácido gama butírico (Tian y col., 2004), proporcionando de esta manera, importante evidencia del rol inmunomodulador de los neurotransmisores. Así, las catecolaminas (ACh y NA/A), han sido implicadas en la regulación, tanto de la inmunidad innata como de la inmunidad adquirida, al modular la eficiencia de la presentación antigénica por células dendríticas, 
la expansión y diferenciación de linfocitos, la migración y tráfico de las células inmunocompetentes, la supresión de la respuesta inmune celular y la estimulación de la respuesta inmune humoral (Steinman , 2004).

Se ha descrito además, que células del sistema inmune pueden sintetizar y liberar neurotransmisores como acetilcolina (Kawashima y col., 2007), serotonina (O'Connel y col., 2006), noradrenalina/adrenalina (Nishibori y col., 2003) y dopamina (Beck y col., 2004; Cosentino y col., 2007).

Los neurotransmisores dopamina y glutamato interactúan con los respectivos receptores expresados por linfocitos $\mathrm{T}$, para activar $\mathrm{o}$ suprimir las funciones linfocitarias, incluyendo la secreción de citoquinas, la proliferación, recirculación y "homing" de estos linfocitos (Besser y col., 2005, Watanabe y col., 2005). Además, durante el proceso de presentación antigénica, las células dendríticas pueden liberar glutamato que inicialmente inhibe la activación de linfocitos TCD4+, a través de señales transducidas por el receptor metabotrópico GluR5 (mGluR5), expresado en la superficie de estos linfocitos (Pacheco y col., 2007; Pacheco y col., 2006). Sin embargo, si el estímulo glutamatérgico es muy alto, se induce en los linfocitos TCD4+ la expresión del receptor mGluR1 que transducirá señales que contrarrestan las señales inhibitorias transducidas por mGluR5, al tiempo que inducen la diferenciación hacia el fenotipo Th1 (Pacheco y col. 2005; Pacheco y col. 2006). Se ha demostrado además, que los linfocitos $\mathrm{T}$ no sólo pueden expresar receptores, tanto nicotínicos como muscarínicos para acetilcolina, sino que también expresan el transportador de este neurotransmisor y son por lo tanto capaces de almacenar ACh en vesículas citoplasmáticas (Kawashima y col., 1998; Kawashima y Fuji, 2003). Otro mecanismo de activación de linfocitos $\mathrm{T}$, es el sistema serotoninérgico dado que, luego de su maduración, las células dendríticas son capaces de expresar el transportador de serotonina, que le permite capturar este neurotransmisor desde el medio extracelular, para almacenarlo en vesículas intracelulares. A partir de estas vesículas se producirá luego la liberación de serotonina, para activar linfocitos $\mathrm{T}$ que expresan el receptor para 5-HT (O'Connell y col., 2006).
Como se ha mencionado en párrafos anteriores, los órganos linfoides secundarios se encuentran inervados por fibras nerviosas simpáticas que almacenan dopamina y los propios linfocitos son capaces de sintetizar y/o almacenar esta catecolamina, que puede actuar a través de distintos de receptores de membrana, denominados D1, D2, D3, D4 y D5. (Levite, 2008; Basu y col., 2010.). Estos receptores dopaminérgicos se separan en dos clases o categorías distintas: la clase denominada D1, incluye a los receptores D1 y D5, que cuando son estimulados activan la adenilato ciclasa y, por lo tanto, aumentan los niveles intracelulares de AMP cíclico (AMPc) y conducen a una disminución en la proliferación celular. La clase denominada D2, incluye, en cambio, a los receptores D2, D3 y D4, que inhiben la adenilato ciclasa y por lo tanto disminuyen los niveles intracelulares de AMPc, estimulando la proliferación celular. (Levite, 2008, Basu y col., 2010, Pacheco y col., 2009)). La estimulación de los receptores de tipo I se ha asociado con la diferenciación de linfocitos $\mathrm{T}$ CD4+ en la subpoblación Th17, que se ha relacionado con procesos inflamatorios y con autoinmunidad (Lee y col., 2009). La estimulación del receptor D2 promueve la secreción de IL-10, citoquina antiinflamatoria que regula negativamente la función de células $\mathrm{T}$ efectoras (Besser y col., 2005).

En el sistema nervioso central, la neurotransmisión dopaminérgica ha sido asociada a funciones motoras, percepción del dolor, secreción hormonal, motivación y placer (Wise, 2008) y su desregulación ha sido relacionada a desórdenes neurológicos como la enfermedad de Parkinson (Hirsh y Hunot, 2009).

\subsection{Respuesta inmune e inflamación en enfermedades neurodegenerativas.}

Muchos de los DAMPs son proteínas nucleares o citosólicas (ácido úrico, proteínas de estrés o de shock térmico hsp, cromatina, nucleosomas, proteínas HMGB1, DNA nuclear), que cumplen funciones intracelulares muy definidas, pero que son liberadas de la células luego de un daño tisular (Kono y Rock, 2008). Así ocurre, por ejemplo, con la proteína nuclear HMGB1 o anfoterina (HMGB1: high mobility group box-1), que se une normalmente al DNA nuclear 
estabilizando los nucleosomas, pero que en situaciones de daño tisular puede ser pasivamente liberada por células necróticas, o bien activamente secretada por neuronas y otros tipos celulares activados (Lotze y Tracey, 2005; Rauvala y Rouhiainen, 2007; Tian y col., 2009).

La identidad de los ACAMPs no ha sido completamente dilucidada, pero incluye fosfatidil serina, ácidos nucleicos, hidratos de carbono y la forma oxidada de liproteínas de baja densidad (Griffiths y col., 2007).

Los receptores que reconocen patrones moleculares de distintos agentes infecciosos se encuentran tanto en la superficie celular como en distintos compartimientos intracelulares e incluyen: los receptores TLR (TLR: Toll Like Receptors), los receptores NRL (NLR:
Nucleotide- and oligomerización domain (NOD)like receptor), los receptores RLR (RLR: retinoic acid inducible gene-1 (RIG-1) like receptor) y los receptores CLR (C-type lectin receptor). La familia mejor caracterizada de PRRs corresponde de a los receptores TLR que, al parecer, no sólo son capaces de reconocer moléculas propias de distintos agentes infecciosos (Tabla 1), sino que también pueden reconocer moléculas endógenas liberadas por células propias en proceso de necrosis o moléculas expresadas como consecuencia de alteración o daño tisular en enfermedades inflamatorias crónicas como arterioesclerosis, diabetes tipo 2, y artritis reumatoide, y que son reconocidas por los receptores TLR-2 y TLR-4 (Baccala y col., 2009; Balistreri y col., 2009, Geijtenbeek y Gringhuis, 2009).

Tabla 1. Patrones moleculares reconocidos por receptores Toll

\begin{tabular}{cc}
\hline TLR & LIGANDO \\
\hline Dímero de superficie TLR-1 & Lipoproteínas, Péptidoglicanos \\
Dímero de superficie TLR-2 & Péptidoglicanos, Zimosan, Lipoarabinoman \\
Dímero de superficie TLR-1/TLR-6 & Péptidos acetilados \\
Dímero de superficietlr-2/TLR-6 & Lipoproteínas de micoplasma \\
Monómero intracelular TLR-3 & RNA doble hebra viral \\
Dímero de superficie TLR-4 & Lipopolisacárido, Glicolípidos \\
Monómero de superficie TLR-5 & Flagelina \\
Monómero intracelular TLR-7 & RNA monohebra viral \\
Monómero intracelular TLR-8 & RNA monohebra viral \\
Monómero intracelular TLR-9 & DNA bacteriano no metilado rico en CpG \\
Monómero de superficie TLR-11 & Profilina de protozoos \\
\hline
\end{tabular}

Estos hallazgos han conducido a preguntarse si los TLRs pueden también contribuir o desencadenar una respuesta inflamatoria en las enfermedades neurodegenerativas (Balistreri y col, 2009; Glass y col, 2010), puesto que las células microgliales y los astrocitos del SNC, no sólo expresan receptores Toll sino también receptores purinérgicos capaces de responder al ATP liberado por las células, luego de su muerte, daño traumàtico o isquemia (Di Virgilio y col., 2009) y los llamados "scavenger receptors", involucrados en la captura de proteínas oxidadas y de células apoptóticas (Husemann y col., 2002).

En las enfermedades neurodegenerativas como Alzheimer (AD: Alzheimer Disease), Parkinson (PD: Parkinson's Disease), Huntington (HD:
Huntington's Disease), esclerosis múltiple (MS: Multiple Sclerosis) y esclerosis lateral amiotrófica (ALS: Amyotrophic Lateral Sclerosis), aún cuando existe un mecanismo especifico y distinto que desencadena cada enfermedad, en todas ellas existe un componente inflamatorio asociado a la disfunción y muerte neuronal. Ello ha llevado a sugerir que la reacción inflamatoria $y$ especialmente la activación de células de la microglia deben estar necesariamente involucradas en la patogénesis de estas enfermedades neurodegenerativas (Villoslada y col., 2008; Schwartz y col, 2006a, b). Así, en diversos modelos animales de la Enfermedad de Parkinson, se ha descrito que la inyección intracraneal de 6-hidroxidopamina conduce a una reacción glial que involucra células microgliales y 
astrocitos (He y col., 2001; Depino y col., 2003; McGer y col., 2003) Sin embargo, la participación activa o reactiva de células de la inmunidad innata (en particular de células gliales) y de linfocitos T y $B$ reclutados desde la periferia, en la patogénesis de estas enfermedades degenerativas, no está aún resuelta, puesto que su activación y participación en la neuroinflamación podría ser consecuencia y no causa del proceso neurodegenerativo (Graber y Strait, 2010).

La esclerosis lateral amiotrófica es una enfermedad del adulto de etiología hasta ahora desconocida y caracterizada por la pérdida selectiva de neurona motoras lo que conduce a una debilidad muscular progresiva, atrofia muscular y eventual parálisis y muerte dentro de los 5 años de aparecidos los primeros síntomas (Swarup y Julien, 2010). La neuroinflamación es una característica fundamental en ALS y parece involucrada en la activación de células de la microglia y en el infiltrado de linfocitos $\mathrm{T}$, en los sitios de daño neuronal (Appel y col., 2009). Aproximadamente el $10 \%$ de los casos de ALS son de origen familiar $y$ se ha asociado a mutaciones en el gen que codifica la $\mathrm{Cu} / \mathrm{Zn}$ superóxido dismutasa 1 (SOD1). El mecanismo de neurodegeneración no está todavía claro, aún cuando se sospecha que las mutaciones SOD1 podrían inducir un plegamiento $\mathrm{y}$ agregado anormal de proteínas. Esta alteración conduce finalmente a daño y muerte neuronal, dado que la liberación de estas proteínas mal ensambladas activarían células de la microglia e iniciarían los ciclos de propagación de neurotoxicidad, al reclutar y activar linfocitos T CD4+ (Appel y col, 2009; Swarup y Julien, 2010).

La esclerosis múltiple, es una enfermedad inflamatoria crónica del SNC, caracterizada por la presencia de placas o áreas focales de demielinización inflamatoria de la substancia blanca en el cerebro y la médula espinal (Trapp y Nave, 2008). La enfermedad ocurre, en individuos genéticamente predispuestos, luego de su exposición a un agente ambiental que desencadena la infiltración del SNC por linfocitos $\mathrm{T}$ específicos, activados contra la proteína básica de la mielina en la periferia. La reactivación de estos linfocitos $\mathrm{T}$ por células presentadoras de antígeno residentes en el SNC y que presentan fragmentos antigénicos derivados de la mielina, gatilla el reclutamiento de células de la inmunidad innata que se involucrarán en la demielinización y el daño neuronal tanto en el cerebro como en la médula espinal (Goverman, 2009). Los signos clínicos de MS incluyen: ataxia, pérdida de la coordinación, hiperreflexia, alteraciones visuales y sensoriales, fatiga y problemas cognitivos. Sin embargo, la severidad y frecuencia de los síntomas clínicos, del daño a nivel central y el curso de la enfermedad, varían enormemente entre los distintos pacientes, el $85 \%$ de los cuales presentan periodos de remisión de los síntomas y signos, pero que inevitablemente desarrollan un daño progresivo en el curso de los años (Goverman, 2009). La inducción de encefalomielitis experimental autoinmune (EAE) en ratones inmunizados con antígenos derivados de la mielina, o transferidos adoptivamente con $\mathrm{T}$ específicos para la mielina, han permitido reproducir el infiltrado inflamatorio y la desmielinización observada en la esclerosis múltiple, apoyando la idea que esta enfermedad tiene un componente autoinmune que implica la participación de linfocitos Th1, Th17 y TCD8 y de macrófagos/microglia (Goverman, 2009, Gandhi y col., 2010; Siffrin y col., 2010).

La enfermedad de Parkinson (PD) es uno de los desórdenes neurodegenerativos más frecuentes. $\mathrm{Su}$ etiología es desconocida y se caracteriza por la pérdida de neuronas dopaminérgicas en la sustancia nigra (SN), ubicada en la región de los ganglios basales en la base del cerebro. Desde el punto de vista clínico, la enfermedad se caracteriza por disfunciones motoras que incluyen movimientos lentos, temblor en reposo, rigidez y alteraciones del equilibrio, a lo cual se agregan alteraciones psiquiátricas (Hirsch y Hunot, 2009, Thomas, 2009). En relación a los mecanismos celulares que conducen a muerte neuronal en el curso de la Enfermedad de Parkinson, se ha sugerido que toxinas, factores genéticos, disfunciones mitocondriales y estrés oxidativo podrían encontrarse entre sus eventuales causas (Dauer y Przedborski, 2004).

Aunque distintas, estas enfermedades comparten algunas características patogénicas como: inflamación, mutación de ciertos genes, agregados proteicos inadecuados o anormales (como los cuerpos de Lewy en la Enfermedad de Parkinson y las placas amiloides en el Alzheimer), que gradualmente comprometen el funcionamiento neuronal; también comparten alteraciones bioquímicas que afectan el metabolismo oxidativo y la función mitocondrial y que, inevitablemente, 
conducen a un proceso de apoptosis neuronal (Dhib-Jalbut y col., 2006).

La reacción inflamatoria en un mecanismo homeostático complejo destinado a proteger la integridad de los organismos frente a diversos agentes o procesos nocivos, tanto exógenos como endógenos $\mathrm{y}$, en relación al $\mathrm{SNC}$, parece desempeñar un rol crucial en el desarrollo de las patologías que lo afectan. La inflamación local es un reacción, temprana, inmediata y frecuente, que se desarrolla frente a eventos que conducen a la muerte o daño neuronal y que incluye la activación de pequeñas células gliales (microglia), el influjo de monocitos y linfocitos desde el torrente sanguíneo, la producción de mediadores proinflamatorios como TNF, Il-1 e IL-6, y la fagocitosis o remoción de los detritus neuronales, que finalmente contribuyen a la recuperación y regeneración del tejido dañado y a la eventual restauración funcional.

Las células microgliales (que corresponden a macrófagos residentes en el cerebro y la médula espinal), representan las células más importantes del sistema inmune innato en el cerebro, expresan receptores similares a los receptores Toll (TLRs: Toll-like receptors), responden a ligandos TLR, producen mediadores proinflamatorios y responden rápidamente frente a patógenos o frente al daño tisular, acumulándose en las regiones cerebrales de neurodegeneración o daño. Por otra parte, es interesante señalar que las células microgliales puedan activarse frente a infecciones sistémicas, en ausencia de un compromiso de la barrera hematoencefálica. Además, la inmunovigilancia rutinaria del SNC, requiere el ingreso de linfocitos $\mathrm{T}$ activados, células dendríticas y macrófagos que pueden penetrar el endotelio vascular del cerebro, aún en condiciones aparentemente fisiológicas puesto que, en condiciones normales, los linfocitos $\mathrm{T}$ no pueden ingresar en el parénquima cerebral, acumulándose en los espacios perivascular (Virchow-Robin) y subaracnoideo. Finalmente, el hecho de que los leucocitos no sólo expresan receptores para diversos neurotransmisores (como glutamato, dopamina, acetilcolina y 48 serotonina), sino que también pueden liberarlos, determina que puedan actuar como moduladores autocrinos y paracrinos de la respuesta inmune a nivel del sistema nervioso central.
Así, la activación de células microgliales, de células dendríticas y de macrófagos perivasculares del SNC, frente a la invasión por agentes patógenos o a daño tisular, conduce a la producción de diversas citoquinas proinflamatorias, quimioquinas, radicales superóxidos, óxido nítrico, metaloproteasas y glutamato que resultan indispensables para la erradicación del agente infeccioso y/o la reparación tisular, pero que son también potencialmente neurotóxicos debido a la persistencia del estímulo inflamatorio o a una falla en los mecanismos normales de resolución del proceso (Graeber y Streit, 2010, Glass y col., 2010). La activación de las células microgliales conduce además a la expresión de moléculas MHC (Major Histocompatibility Complex) y de diversas moléculas coestimuladoras, permitiendo que puedan actuar como células presentadoras de antígenos neuronales para los linfocitos $T$ presentes en el SNC. De esta manera el desarrollo de una respuesta linfocitaria, agravará el daño primario del tejido neuronal producido por un trauma físico, por necrosis luego de un infarto cerebral o como resultado de la conformación anormal de proteínas y su consecuente agregado y acumulación intracelular neurotóxica. Así parece ocurrir con la neurodegeneración inducida por el depósito de amiloide beta y la proteína tau en la Enfermedad de Alzheimer, la acumulación de alfa sinucleína (cuerpos de Lewy) en neuronas dopaminérgicas en la Enfermedad de Parkinson y de la superóxido dismutasa en la Esclerosis Lateral Amiotrófica familiar, ( Huang y col., 2009; Czlonkowska y Kurkowska, 2010; Goedert y col., 2010; Schulz-Schaeffer, 2010

\section{Referencias}

1. Appel, S.H.; Beers, D.R.; Henkel, J.S. 2009. $\mathrm{T}$ cell-microglial dialogue in Parkinson's disease and amyotrophic lateral sclerosis : are we listening. Trends Immunol. 31: 7-17

2. Baccala, R., Gonzalez-Quintial, R., Lawson, B. R., Stern, M.E., Kono, D.H., Beutler, B., Theofilopoulos, A. N. 2009. Sensors of the innate immune system: their mode of action. Nat. Rev. Rheumatol. 5, 448-456

3. Balistreri, C.R., Colonna-Romano, G., Lio, D., Candore, G., Caruso, C. 2009. TLR4 
Polymorphisms and Ageing: Implications for the Pathophysiology of Age-Related Diseases. J. Clin. Immunol. 29_406-415.

4. Basu, B., Sarkar, Ch., Chakroborty, D., Ganguly, S., Sho,e, S., Dasgupta, P.S., Basu, S. 2010. D1 and D2 dopamine receptor mediate inhibition of activated norma $\mathrm{T}$ cell proliferation is lost in $\mathrm{T}$ leukemic cells, Jurkat. J. Biol.Chem. (en prensa).

5. Baccala, R., Gonzalez-Quintial, R.; Lawson, B.R.; Sterna, M.E.; Kono, D.H.; Beutler, B. Theofilopoulos, N. 2009. Sensors of the innate immune system: their mode of action. Nat. Rev. Rheumatol. 5:448-456.

6. Beck, G.C., Brinkkoetter, P., Hanusch, C., Schulte, J., Van Ackern, K., Van der Woude, F.J., Yard, B. A. 2004. Clinical review: Immunomodulatory effects of dopamine in general inflammation. Critical Care 8: 485491.

7. Bellinger, D. L. Millar, B.A., Perez, S., Carter, J., Wood, C., ThyagaRajan, S., Molinaro, C., Lubaan Ch., Lorton, D. 2008. Sympathetic modulation of immunity: relevance to disease. Cell. Immunol. 252: 2756.

8. Besser, M. J., Ganor. Y., Levite, M. 2005. Dopamine by itself activates either D2, D3 or D1/D5 dopaminergic receptors in normal human T-cells and triggers the selective secretion of either IL-10, TNFa or both. J. Neuroimmunol. 169: 161-171.

9. Czlonkowska, A.; Kurkowska-Jastrzeska, I. 2010 Inflammation and gliosis in neurological disease-clinical implications. J. Neuroimmunol (en prensa)

10. Cosentino, M., Fietta, A.M., Ferrari, M., Rasini, E., Bombelli, R., Carcano, E., Saporiti, F., Meloni, F., Marino, F., Lecchini, S. 2007. Human 49 $\mathrm{CD} 4+\mathrm{CD} 25+$ regulatory $\mathrm{T}$ cells selectively express tyrosine hydroxylase and contain endogenous catecholamines subserving an autocrine/paracrine inhibitory functional loop. Blood 109: 632-642.
11. Dauer, W.; Przedborski S. 2003. Parkinson's Disease: Mechanisms and Models. Neuron 39:. 889-909.

12. Depino, A.M.; Earl, C.; Kaczmarczyk, E.; Ferrari, C.; Besedovsky, H.; Del Rey, A.; Pitossi, F.J.; Oertel, W.H. 2003. Microglial activation with atypical proinflammatory cytokine expression in a rat model of Parkinson's disease Eur. J. Neurosci. 18: 2731-2742.

13. Dhib-Jablbut, S., Arnold, D.L., Cleveland, D.W., Fisher, M., Friedlander, R. M., Mouradian, M.M., Prezedborski, S., Trapp, B.D., Wyss-Coray, T., Yong, V.W. 2006. Neurodegeneration and neuroprotection in multiple sclerosis and other degenerative diseases. J. Neuroimmunol. 176: 198-215.

14. Di Virgilio, F., Ceruti, S., Bramanti, P., Abbracchi, M.P. 2009. Purinergic signalling in inflammation of the central nervous system. Trends Neurosci. 32: 79-87

15. Elenkov, I.J., Wilder, R.L.., Chrousos, G.P. and Vizi, E.S. 2000. The Sympathetic Nerve-An Integrative Interface between Two Supersystems: The Brain and the Immune System. Pharmacol Rev. 52: 596631.

16. Engelhardt, B.; Ransohoff, R. M. 2005. The ins and outs of T-lymphocyte trafficking to the CNS: anatomical sites and molecular mechanisms Trends Immunol 26: 485-495.

17. Franco, R., ., Pacheco, R., Lluis, C., Ahern, G.P. Ahern, O'Connell, P. J. 2007.The emergence of neurotransmitters as immune modulators. Trends Immunol. 28: 400-407.

18. Gandhi, R.; Laroni, A.; Weiner, H.L. 2010. Role of innate immune system in the pathogenesis of multiple sclerosis. J. Neuroimmunol. 221: 7-14.

19. Geijtenbeek, B.H.; Gringhuis, S.I. 2009. Signalling through C-type lectin receptors: shaping immune responses. Nat. Rev. Immunol. 9:465-479.

20. Glass, C.K.; Saijo, K., Winner, B., Marchetto, M.C., and Gage, F.H. 2010. Mechanisms 
underlying inflammation in neurodegeneration. Cell 140: 918-934.

21. Goedert, M.; Clavagera, F.; Tolnay, M. 2010. The propagation of prion-like protein inclusions in neurodegenerative diseases Trends Neurosci. 33: 317-325.

22. Goverman, J. 2009. Autoimmune T cell responses in the central nervous system. Nat. Rev. Immunol. 9: 393-407.

23. Graeber, M.B. and Streit, W.J. 2010. Microglia: biology and pathology Acta Neuropathol. 119: 89-105.

24. Griffiths, M.; Neal, J.W.; Gasque P. 2007. Innate immunity and protective neuroinflammation: New emphasis on the role of neuroimmune regulatory proteins. Int. Rev. Neurobiol. 82: 29-55.

25. Hanisch, U.K. and Kettenmann, H.(2007. Microglia: active sensor andversatile effector cells in the normal and pathologic brain. Nat. Neurosci. 10: 1387-1394

26. He, Y.; Appel, S.; Le, W. 2001. Minocycline inhibits microglial activation and protects Nigral cells after 6-hydroxydopamine injection into mouse striatum Brain Res. 909: 187-193)

27. Hirsch, E. and Hunot $S$. 2009.Neuroinflammation in parkinsosn's disease: a target for neuroprotection?. Lancet Neurol. 8: 382-397.

28. Huang, X.; Reynolds, A.D.; Mosley, R. L.; Gendelman, H.E. 2009. CD4+ T cells in the pathobiology of neurodegenerative disorders. J. Neuroimmunol. 211: 3-15.

29. Husemann, J., Loike, J.D., Anankov, R., Febbraio. M., Silverstein, S.C.. 2002. Scavenger receptors in neurobiology and neuropathology: Their role on microglia and other cells of the nervous system. Glia 40: 195-202.

30. Kawashima, K., Fuji, T. 2003. The lymphocytic cholinergic system and its contribution to the regulation of immune activity. Life Sci. 74: 675-696.
31. Kawashima, K., Fuji, T., Watanabe, Y., Misawa, H. 1998. Acetylcholine synthesis and muscarinic receptor subtype: mRNA expression in T-lymphocytes. Life Sci. 80: 2314-2319.

32. Kawashima, K., Yoshikawwa, K., Fujii, Y.X., Moriwaki, Y., Misawa, H. 2007. Expression and function of genes encoding cholinergic components in murine immune cells. Life Sci. 80:2314-2319.

33. Kono, H., Rock, K.L. 2008. How dying cells alert the immune system to danger. Nat. Rev. Immunol. 8: 279-289.

34. Lee, Y.K.; Mukasa, R.; Hatton, R.D.; Weaver, C.T. 2009. Deveopmental plasticity of Th17 and Treg cell. Curr. Opin. Immunol. 21: $274-280$

35. Leon-Ponte, M., Ahem, G.P., and O'Connell, P. J. 2007. Serotonin provides an accessory signal to enhance T-cell activation by signaling through the 5-HT7 receptor. Blood 109: 3139-3146.

36. Levite, M. 2008. Neurotransmitters activate T-cells and elicit crucial functions via neurotransmitters receptors. Curr. Opin. Pharmacol. 8: 460-471.

37. Lotze, M.T. and Tracey, K.J. (2005) Highmobility group box 1 protein (HMGB1): nuclear weapon in the immune arsenal. Nat. Rev. Immunol. 5, 331-342

38. McGeer, P.L.; Schwab, C.; Parent, A.; Douder, D. 2003. Presence of reactive microglia in monkey substantia nigra years after 1-methyl-4-phenyl-1,2,3,6 tetrahydropyridine administration. Ann. Neurol. 54: 599-604

39. Nishibori, M., Takahashi, H.K., Mori, S. 2003. The Regulation of ICAM-1 and LFA-1 Interaction by Autacoids and Statins: a Novel Strategy for Controlling Inflammation and Immune Responses. J. Pharmacol. Sci. 92: 712.

40. O'Connell, P.J., Wang, X., Leon-Ponte, M., Griffiths, C., Pingle, S.C., Ahern, G.P. 2006. 
A novel form of immune signaling revealed by transmission of the inflammatory mediator serotonin between dendritic cells and $\mathrm{T}$ cells. Immunobiol. 107: 1010-1017.

41. Pacheco, R., Gallart, T., Lluis, C., Franco, R. 2007. Role of glutamate on T-cell mediated immunity. J. Neuroimmunol. 185: 9-19.

42. Pacheco, R., Oliva, H., Martinez-Navio, J.M.,Climent, N., Ciruela, F., Gatell, J.M., Gallart, T., Mallol, J., Lluis, C., Franco, R. 2006 Glutamate Released by Dendritic Cells as a Novel Modulator of T Cell Activation. J. Immunol. 177: 6695-6704.

43. Pacheco, R., Prado, C:E., Barrientos, M.J., Bernales, S. 2009. Role of dopamine in the physiology of $\mathrm{T}$ cell and dendritic cells.. $\mathrm{J}$. Neuroimunol. 216: 8-19.

44. Rauvala, H. and Rouhiainen, A. (2007) RAGE as a receptor of HMGB1 (Amphoterin): roles in health and disease. Curr. Mol. Med. 7, 725-734

45. Reyes-García, M.G, García-Tamayo, F. 2009. A neurotransmitter system the regulates macrophage pro-inflammatory functions. J. Neuroimmunol. 216: 20-31.

46. Rivest, S. 2009. Regulation of innate immune response in the barin. Nat. Rev. Immunol. 9: 429-439.

47. Saha, B.; Mondal, A.C., Majumder, J., Basu, S., Dasgupta, P.S. 2001b Physiological Concentrations of Dopamine Inhibit the Proliferation and Cytotoxicity of Human CD4+ and CD8+ $\mathrm{T}$ Cells in vitro: $\mathrm{A}$ Receptor-Mediated Mechanism. Neuroimmunomodulation 9: 23-33.

48. Sakagushi, S., Miyara, M., Constantino, C.M., Hafler, D.A. 2010. Foxp3+ regulatory $\mathrm{T}$ cells in the human immune system. Nat. Rev. Immunol. 10: 490-500

49. Sanders, V. M. and Straub, R.H. 2002. Norepinephrine, the $\beta$ adrenergic receptor and immunity. Brain. Behav. Immun. 16: 290-332.
50. Sarkar, Ch., Das, S., Chakroborty, D., Chowdhury, Roy, U., Basu, B., Dasgupta, P.S. and S. Basu, Cutting Edge: Stimulation of Dopamine D4 Receptors Induce T Cell Quiescence by Up-Regulating Kruppel-Like Factor-2 Expression through Inhibition of ERK1/ERK2 Phosphorylation. J. Immunol. 177: 7525-7529.

51. Schulz-Schaeffer W.J. 2010. The synaptic pathology of $\alpha$-synuclein aggregation in dementia with Lewy bodies, Parkinson's disease ans Parkinson'sdisease dementia. Acta Neuropathol. 120: 131-143.

52. Schwartz, M., Butovsky, O., Brück, W., Hanish, U.K. 2006a. Microglial phenotype: is the commitment reversible? Trends Neurosci. 29: 68-74.

53. Schwartz, M., Butovsky, O., Kipnis, J. 2006b. Does inflammation in an autoimmune disease differ from inflammation in neurodegenerative diseases? Possible implication for therapy J. Neuroimmune Pharmacol. 1: 4-10.

54. Siffrin, V.; Vogt, J.; Radbruch, H.; NItsch, R. ; Zipp, F. 2010. Multiple sclerosiscandidate mechanisms underlying CNS atrophy. Trends Neurosci. 33: 202-210.

55. Steinman, L. 2004. Elaborate interactions between the immune and nervous systems. Nat. Immunol 5: 575-581

56. Swarup, V.; Julien, J.P. 2010. ALS pathogenesis : Recent insights from genetics and mouse models. Prog. NeuroPharmacol. Biol. Psychiatry (in press)

57. Takeuchi, O.; Akira, S. 2010. Pattern Recognition Receptors and Inflammation. Cell 140: 805-820.

58. Thomas, B. 2009., Parkinson's Disease: From Molecular Pathways in Disease to Therapeutic Approaches. Antiox.Red. Signaling 11: 2077-2082.

59. Tian, J., Lu, Y., Zhang, H., Chau, C:H., Dang, H.N. and Kaufman, D..L. 2004. $\gamma$ Aminobutyric Acid Inhibits $\mathrm{T}$ Cell Autoimmunity and the Development of 
Inflammatory Responses in a Mouse Type 1 Diabetes Model. J. Immunol. 173: 52985304.

60. Tian, L.; Rauvala, H.; Gahmberg, C.G. 2009. Neuronal regulation of immune response in the central nervous system. Trends Immunol. 30: 91-99

61. Tracey, K.J. 2007. Physiology and immunology of the cholinergic antiinflammatory pathway. J. Clin. Invest. 117: 289-296.

62. Tracey, K.J. 2009. Reflex control of immunity. Nat. Rev. Immunol. 9: 418-428.

63. Tracey, K. J. 2010. Understanding immunity requires more tha immunology. Nat. Immunol. 11: 561-564.

64. Trapp, B.D., Nave, K-A. 2008. Multiple sclerosis: An immune or neurodegenerative disorder?. Annu. Rev. Neurosci. 31: 247-269.

65. Vergara, U. 2009. Linfocitos T reguladores y respuesta inmune. Av. Cs. Vet. 24: 72-79..

66. Vergara, U., Zuñiga, C., Palomo, I. 2002. Regulación de la respuesta inmune. En: Palomo, A. Ferreira, C. Sepúlveda, M. Rosemblatt, U. Vergara (eds) Fundamentos de Inmunología Básica y Clinica: 277-287. Editorial Universidad de Talca, Talca, Chile

67. Villoslada, P.; Moreno, B.; Melro, I.; Pablos, J.L.; Martino, G.; Montalban, X.; Avila, J.; Rivest, S., Acarain, L.; Appel, S.; Khoury, S,J.; McGeer, P,; Ferrer, I.; Delgado, M.; Obeso, J.; Schwartz M. 2008. Immunotherapy for neurological disease. Clin. Immunol. 128: 294-305.

68. Watanabe, Y., Nakayama, T., Nagakubo, D., Hieshima, K., Jin, Z., Katou, F., Hashimoto, K. and Yoshie, O. 2006. Dopamine Selectively Induces Migration and Homing of Naive CD8+ T Cells via Dopamine Receptor D3. J. Immunol. 176: 848-856.

69. Wing, K, Sakagushi, S. 2010. Regulatory T cells exert checks and balances on self tolerance and autoimmunity. Nat. Immunol. 11: 7-13
70. Wise, R.A. 2008. Dopamine and Reward: The Anhedonia Hypothesis 30 years on Neurotox. Res. 14 :169-183. 